UDK 613.7

\title{
COMPARATIVE ANALYSIS OF EXPECTABLE CONSEQUENCES OF IMPACT ON THE HEALTH OF CITIZENS OF DIFFERENT SCENARIO CONDITIONS OF TIME COMPUTATION
}

\author{
V.B. Alekseyev ${ }^{1}$, D.A. Kiryanov ${ }^{1}$, M. Tsinker ${ }^{1}$, M.R. Kamaltdinov ${ }^{1}$, O.S. Novikova ${ }^{2}$ \\ ${ }^{1}$ FBSI "Federal Scientific Center for Medical and Preventive \\ Health Risk Management Technologies", \\ 82, Monastyrskaya St., Perm, 614045, Russia, \\ 2 FSBEI HPE "Perm State National Research University", \\ 15, Bukireva St., Perm, 614990, Russia
}

Abstract. To analyze expectable consequences of impact on the life and health of citizens of different scenarios of time computation, as the main impact factor the deviation (offset) of administrative time with respect to astronomical time - absolute jetlag coefficient was considered. As the indicators of response to the impact factor the indicators of population morbidity of entities of the Russian Federation were used.

On the basis of constructed statistical correlations the optimal levels of absolute jetlag coefficient were determined. By the risk criteria of additional primary children morbidity the optimal values of the absolute jetlag coefficient are in the range 56-92 min.; by the risk criteria of additional primary morbidity of adults: 71-129 min.

The assessment of the expectable consequences on the health of citizens of one or another scenario of time computation in the entity of the Russian Federation carried out by estimating the absolute jetlag coefficient, formed at a certain scenario, showed that at the current distribution of the RF entities across time zones, none of the analyzed scenarios for computing time would be optimal for absolutely all regions. Moreover, 12 entities of the Russian Federation do not reach the optimal values of the absolute jetlag coefficient in any of the scenarios of time computation considered.

Time computation in accordance with its astronomical time ((zone, geographical) is a non-optimal time by the criteria of minimizing the risk of additional morbidity in all entities of Russia and cannot be considered as a choice. Minimizing the risk from the use of each of the scenarios of time computation discussed (permanent summer, with seasonal transitions summer/winter) is possible only with the revision of the number of time zones and their composition in order to bring the administrative time offset values in the entities of the Russian Federation to the optimum values, which minimizes the risk of additional morbidity, associated with jetlag.

The least redistribution to minimize the risk scenario is required by the scenario of time computing with seasonal transitions to "winter" and "summer" time (required reconstruction of two time zones and taking a decision on the redistribution of relative time zones for 22 entities of the Russian Federation).

Key words: time computation, absolute jetlag coefficient, additional morbidity, risk minimization.

The issues of population health risk management might have practical appliance in the sphere of harmonization of the time keeping system in the country. The legal basis of time keeping in the Russian Federation at the current moment is determined by the Federal Law \# № 107-FL dated 03.06.2011 «On time keeping» which determines time zones and their borders in the country with the account of the borders of the Russian Federation subjects. The Resolution which was adopted in support of developing the given law and named the Resolution of the RF

(C) Alexeyev V.B., Kiryanov D.A., Tsinker M.Y., Kamaltdinov M.R., Novikova O.S., 2014

Alexeyev Vadim Borisovich - DSc in Medicine, Deputy Director for organizational and methodological work (e-mail: vadim@fcrisk.ru; tel.: 8 (342) 236-32-70).

Kiryanov Dmitriy Aleksandrovich - CTS, Head of Department of Mathematical Modeling of Systems and Processes (e-mail: kda@fcrisk.ru; tel.: 8 (342) 237-18-04).

Kamaltdinov Marat Rishidovich - junior research associate (e-mail: kamaltdinov@fcrisk.ru; tel.: 8 (342) 237-18-04).

Tsinker Mikhail Yurievich - junior research associate (e-mail: cinker@fcrisk.ru; tel.: 8 (342) 237-18-04).

Novikova Olga Sergeevna - master's degree student (e-mail: root@fcrisk.ru; tel.: 8 (342) 237-18-04). 
Government \# 725 dated 31.08.2011 «On the constituent territories forming each time zone and on the order of time keeping in time zones as well as admitting that some Resolutions of the Russian Federation have lost their power» abolished time shifts: “...Moscow time is kept in the national time scale of the Russian Federation UTC plus 4 hours. The seasonal time shift is not executed, the time and minute keeping within the calendar year is not altered". When determining the necessity of the transfer to constant summer time and forming the necessary number of time zones in the Russian Federation the developer of normative acts (the Department of state policy in the sphere of technical regulation and provision of measurement unity of the Ministry of Industrial Trade of the Russian Federation) tried to take into account all the possible factors: medical-biological; economic; production and managerial; national and geopolitical; legislative; international; metrological. But it was the factor of increasing the efficiently used by the population light time of the day that was a deciding factor. The objective analysis of different options of time keeping in Russia using annual summer and winter time shifts or without using these shifts as well as the one with the chosen time zone shift for each subject of the RF from Greenwich time (from the point of view of rational usage by the population of the light time of the day and, accordingly, the duration of artificial lighting usage by entities, enterprises, organizations) allowed to form the system of time zones in the way that the highest position of the sun above the horizon (astronomic midday) was not at 12 o'clock but in the middle of population active period in accordance with the typical for the regions schedule of the workday. Then the 'losses' of the light time of the day would be minimal [4].

The current time keeping system determines the constant shift of the administrative time compared to the astronomic one for plus two hours. The difference in time with Europe in the winter period started making three hours.

Just to be fair it is worth mentioning that 2-hour desynchonosis is marked far not in all subjects of the Russian Federation. Just because of the mass shift of regions, areas, republics in the neighbouring (previous) time zones in the period of 1981-2010 the factual administrative time is 2 hours ahead of the zone time (astronomic) only in 22 subjects of the Russian Federation; 1 hour ahead in 54; 7 regions of Russia, among which we can name Komi, Nenets autonomous district, the east of Chukotka, live in accordance with their geographic time.

The claims of citizens at all the levels of state authorities and sociological research show that part of the population is quite subjective in the feeling of the negative changes in their health condition associated with the change of time keeping system [2].

The conclusions offered for discussion in the Mass Media and drawn based on few researches on the problem of time-keeping system change are quite controversial, quite often 
trend-driven and are classified upon the scenario of time-keeping which is being justified by them:

- time keeping is possible only in accordance with its astronomic (zonal) distribution as the shift of time doesn't imply any significant economic benefits. Moreover, it leads to the losses (in agriculture) and causes significant negative trends in the population health indicators [1];

- time keeping is necessary and possible to administer and manage ('decree annual'; 'decree +1 hour' for the summer period; 'decree +1 hour' annually) as there is economic justification and there are no long-term and grievous implications for individual health because of endogenic mechanisms of self-regulation providing adaptation to external desynchronosis which is confirmed by the absence of dependence of population health indicators (mortality) on the applied systems of time keeping. Moreover, the number of road accidents with mortal cases and serious injuries decreases [5].

With financial support of the Ministry of Education and Science of the Russian Federation, the Federal Budgetary Science Institution 'Federal Scientific Center of MedicalPreventive Technologies of Population Health Risk Management' has conducted a comparative analysis of objective implications of potential influence on health and well-being of people under various scenario conditions of time-keeping - in the population area and in the vulnerable population groups.

The purpose of the research - evaluation and choice of the efficient scenario of timekeeping (under the criteria of minimal risk for population health)

Materials and methods. The solution of the task of comparative assessment of time keeping scenarios on medical-biological criteria was multi-faceted and based on several information sources and was conducted in three directions:

- theoretical researches;

- epidemiologic-statistical researches;

- experimental researches.

Theoretical researches were conducted by the method of analytical observation of scientific publications devoted to pathogenic mechanisms of various scenarios conditions influence of time keeping on the stability of adaptation-compensatory mechanisms of maintenance homeostatic intersystem circadian rhythms on the subcell, cell, organ and body levels; on the mechanisms of internal desynchronosis development and the most significant integral indicators allowing to evaluate the degree and seriousness of desynchronosis and/or the paces of resynchronizing; on the most probable models of somatic pathology development 
conditioned by desynchronosis, conditions, releasing-factors and pathofunctional mechanisms of their realization into classes of diseases and certain nosologic units.

Epidemiologic-statistical researches were based on the analysis of population level information aggregated in the subjects of the Russian Federation. With this, within the framework of statistic researches there was held the study of the consistent patterns of regional distribution of population health indicators in connection with the current existing time keeping system. Epidemiologic researches contained a detailed comparative analysis of health indicators on the neighboring territories considerably differentiating in time keeping systems but similar on geographic location, climatic and social economic conditions. Standard means of office applications were used to process data, including MS Excel 7.0; Statistica Advanced 9.0; Statistica Automated Neural Networks 9.0; PASW Statistics 18.0. The preliminary analysis of data, visualization of the results were made in MS Excel, the methods of modeling and hypothesis verification were held using the software complex Statistica.

The main idea of such statistic researches at the level of regions of the Russian Federation is the suggestions that the shift of administration time from astronomic time changes the share of the light time of the day falling onto the period of human vigilance and has negative impact on the health condition.

Taking into the account the complexity and uncertainty of such hypothesis verification at an individual level, the statistic research evaluated the impact at the level of large populations. Moreover, in order to exclude the factor of evaluation subjectivity, as the basis statistic material there has been used open legitimate information gathered and offered by special authorized bodies. The source of information for conducting statistical researches was the following reference materials published by the Ministry of Healthcare of Russia:

- «Morbidity of the Population of Russia» (FSBI «Central Scientific and Research Institute of organization and informational support of healthcare»);

- «Medical-demographic indicators of the Russian Federation» (Ministry of Healthcare of Russia).

The assessment of territorial distribution of health indicators was conducted over the period of 2010-2011 when the system of time division of the Russian Federation was changed (there was changed the number and constituents of time zones) and the change of time keeping system was implemented (transfer to the constant summer time).

As the methodology of hypothesis verification there was used the system analysis based on the methods of mathematic statistics and risk assessment [3]. 
As the main operating factor at statistic research there was considered the digression of administrative time from astronomic (zonal) which is described through the absolute desynchronosis index. The sources of information for calculation of the absolute desynchronosis index were:

- distribution of the regions of the Russian Federation according to time zones reflected by the Resolution of the Government of the RF \# 275 dated 31st of August 2011;

- geographic longitude and latitude of regional centers.

To calculate the difference between the administrative and astronomic times on the territory of the Russian Federation there was determined astronomic time for each regional center based on its geographic location and coordinates with the precision up to minutes.

Modeling the dependences of health indicators on time keeping parameters was effected by the method of regression analysis with the further verification of statistic hypothesis on the correlation of the model with statistic data which was based on dispersion analysis and Fisher criterion. Within the framework of this procedure there was effected the calculation of the determination model index (R2) reflecting the contribution of the factor into the dispersion of the variable dependence. Besides, there was the expertise to check the impact and correspondence of theoretically based biologic mechanisms of potential influence of time keeping system on human health.

Within the framework of the analysis and generalization of the modeling results there was performed calculation of the number of additional cases conditioned by the change of time keeping system. The calculations were based on the models of dependences of separate health indicators on absolute desynchronosis index. The calculation of additional cases was performed for separate regions corresponding with the following requirements:

- health indicator (morbidity or mortality) has the values higher than the average Russian level;

- absolute desynchronosis index is beyond the range of optimal values.

When calculating additional cases there was taken into account the model determination index.

The main goal of conducting epidemiologic researches was to determine possible discrepancies in health condition of all population and separate 'vulnerable' groups for modeled territories having a considerable discrepancies in time keeping.

Two major industrial cities and administrative centers of neighbouring subjects of the RF were chosen as model territories. They are Perm with the absolute desynchronosis index of 144 minutes and Izhevsk with the absolute desynchronosis index of 24 minutes. 
Within the framework of the current scientific-research work as the vulnerable group of population there were considered children (0-15 years old) and elderly people (over 60 years old).

As the source of information there were used prepared data of the population references to ambulance and to medical institutions (as for the Territory Fund of Compulsory Medical Insurance [TFCMI] data).

There were researched the data for performed and cancelled time shifts:

- one hour ahead: 29.03.2009, 28.03.2010 (Udmurt Republic this year hasn't transferred to the summer time in order to move to Moscow time zone) 27.03.2011;

- one hour back: 25.10.2009, 31.10.2010;

- 30.10.2011 (the date of cancelled winter time shift).

The conditions of the analysis presupposed the research of the 24 hour dynamics of references over 2 week period before and 2 week period after the date of the effected or cancelled time shift.

The program of epidemiologic researches presupposed the analysis of references of modeled territories population for medical help as for the data gathered in the system of Compulsory Medical Insurance and allowed to conduct research of all the cases of reference for medical help (as for rosters offered for charge by medical institutions) as well as for the data reflected in the information service of city stations of ambulance reflecting acute illness cases.

The research of the dynamics of population references for medical help included comparative assessment of the indicators on the following options:

Comparison of the indicators dynamics among model territories over the same time intervals;

Comparison of indicators dynamics on separate model territory on time intervals correlating to different scenarios of time keeping.

When preparing the materials for analysis they took into account of weekly fluctuations of reference indicators. The account of weekly component was conducted by means of the 'sliding window' - a consecutive averaging the number of cases of reference for medical help within a week ( \pm 3 days from the date of the calculation). Smoothing the initial date by means of the 'sliding window' method allows to eliminate the influence of the disturbing effect connected with the change of workdays and weekends.

The comparison of dynamic data rows was performed on the basis of the comparison criterion for dependent selections. 
The goals of the experimental studies were to determine the influence of various scenarios conditions of time keeping on the life and well-being of living bodies and research of polymorphism of genes of a human being as a marker of forming hereditary predisposition to adaptation/deadaptation in the situation of desynchronosis.

The experimental studies of the influence of various scenarios conditions of time keeping on life and well-being of living bodies was conducted by means of modeling the desynchronosis among 6 adult and 1 baby of primates represented by Japanese macaques (Lat. Macaca fuscata). In the course of experimental studies there was conducted a research of the influence from shifting the feeding regime (in comparison with the natural light day) on life and activity of primates and change in parameters of behavior expressed in locomotion (animals' moving in space conditioned by their active actions), grooming (active behavior of animals aimed at cleaning their body surface), eating habits (food), aggression. Besides, there was also studied the degree of stress of animals by means of measuring the level of hormones in their urine. Determination of behavioral parameters consisted of visual observation of the animals. The measurement of their biochemical indicators reflecting the level of primate stress (cortisol and corticosterone) was performed with the help of noncontact analysis (IFA - immunofluorescent assay) of the level of hormones in urine samples.

Experimental studies of the possibility of inheriting the predisposition for adaptation/deadaptation in the situation of desynchronosis were performed by means of studying polymorphism of marker human genes on two model territories (Perm region and Undurt Republic) the population of which live in the conditions of different values of desynchronosis. There have been selected 50 pairs of umbilical cord blood samples of new born babies and blood of expectant mothers.

On the basis of written data as marker genetic indicators there were chosen the genes of melatonin receptors MTNR1B, MTNR1A and clock-genes Per2 and Cry1 (periodic and cryptochrome) as a criterion of possible violations - the degree of their polymorphism (SNP).

There was calculated the percent of homozygotes and heterozygotes. The frequencies of allels were used for the further calculation of their spread in populations. The calculated distribution of allels studied in the populations was compared with the quoted one according to the special materials sources.

Results and discussion. On the basis of scientific publications analysis it is theoretically based that there exists risk of development of functional disorders and pathologic conditions in organs and body systems as a response to desynchronosis which develops under administration scenarios of time keeping presupposing its seasonal or annual shift in comparison with the initial 
astronomic (geographic, zonal, solar). The desynchronosis conditions the development of nonspecific somatic pathology expressed in a group of diseases and certain nosologic units which could be considered as 'markers' for it because of coincidence of the beginning and development of the pathology with the breakdown in adaptation in the periods of time keeping changes.

Within the frameworks of epidemiologic-statistic direction there has been conducted modeling of negative or positive implications of this or that time keeping scenario.

In the course of statistic modeling there have been analysed:

- 166 dependences of various types of diseases among children population;

-166 dependences for different types of diseases among adult population.

On the basis of the scientific publications data, out of all statistically accurate dependences on the diseases of the population there was made a justified (from the medicalbiologic point of view) choice of 11 markers of desynchronosis groups of diseases and separate diseases for further assessment of the implications from the change of time keeping system. Among those there are eye-diseases and appendages of the eye diseases including myopia; locomotion system and connective tissue diseases; acute inflammations of upper air passages; lever diseases; non-infectious enteritis and colitis; disorders of menstruation cycle among women; symptoms and indicators and digressions from the norm detected during clinic and laboratory research and non-classified in other rubrics; traumas, poisoning and some other implications of external reasons; epilepsy, epileptic status; blood circulation organ diseases.

The obtained statistical models describe the influence of the absolute desynchronosis index on the indicators of initial morbidity of children and adult population with the contribution of desynchronosis into the digression of health indicators of about $8.1 \%$ for children and $7.9 \%$ for aduls. On the basis of the drawn dependences there were determined the optimal levels of the absolute desynchronosis index. According to the risk criteria for additional initial morbidity of children, the optimal values of the absolute desynchronosis index are in the range of 56-92 minutes; for adults - 71-129 minutes.

The analysis of the calculation results allowed to determine the optimal level of the absolute desynchronosis index making 79 minutes for children and 86 minutes for adults. On the whole, it can be concluded that for all groups of the population the optimum of the shift is within the period of an hour and a half in comparison with the astronomic time.

On the basis of the obtained optimal values of the average annual of the absolute desynchronosis index there were performed forecast calculations of additional morbidity cases for children and adult population. The calculations showed that the presence of a significant nonhomogeneity in regional distribution of additional morbidity cases can be explained by the 
peculiarities of regional distribution of desynchronosis values - remoteness of the zones from the optimum. The maximum number of additional cases is forecast in the scenario of constant 'winter' time in Chukotskiy autonomous district, Udmurt Republic, Nenets autonomous district, Samara and Ulyanovsk regions. Under this scenario regions which are today in the conditions of their astronomic (geographic) time will start going ahead of it. For other scenario conditions the distribution of additional cases is changed. Basing on the analysis of general trends it can be concluded that the worse scenario is the constant astronomic time.

This conclusion was confirmed by the results of epidemiologic research conducted on two model territories differentiating in values of desynchronosis and quite comparable on socialeconomic and climatic-geographic location. The city of Perm corresponds to the system of time keeping with the desynchronosis index of more than 2 hours and the city of Izhevsk - with desynchronosis about 0.25 hour.

The comparative analysis of references of the population for medical help (both emergency ambulance and outpatient care) in different years shows absence of steady excess of indicators of one year over another for the city of Perm and a vivid trend to the increase of indicators of reference in 2011 for the city of Izhevsk. This observation is in accord with a potential impact of the time keeping system change which took place in 2010 in the Udmurt Republic and entailed considerable decrease of the light part of the day which fell onto the human activity period (in March 2010 Udmurt Republic adopted Moscow time zone).

Modeling the dependences between the share of the light part of the day falling onto the activity period of the population and the indicators of population references for medical help connected with diseases and traumas allowed to forecast the number of additional morbidity cases for various scenarios. The analysis of the obtained forecast data showed that under the current scenario of time keeping the number of additional morbidity cases in Perm is 10 times lower than in Izhevsk when analysed by all nosologic forms and age groups.

When implementing the time keeping scenario presupposing seasonal observation realized in certain dates by transferring the time 1 hour ahead or back, the risk of negative impact on the body is formed due to the abrupt 'impulse' change of external time synchronizer requiring the tension of adaptation mechanisms for resynchronization of internal biorhythms.

In the theoretic studies it is shown that an hour shift of the external time synchronizer in each side (back or ahead) should not result in such negative consequences for a healthy organism having normal adaptation potential. Thus, the possibility of negative impacts from the factor of time keeping system change for the so called 'vulnerable' groups is admitted. 
The analysis of the change in dynamics of population reference for medical help before and after the seasonal change of time keeping showed that the impact of time keeping change on the health of vulnerable groups of population under the given criterion is expressed indirectly and has a character of trends. With this, at the level of vulnerable groups of the population there is a two-week adaptation to the impact.

The possibility of arising negative implications for the health from the factor of time keeping system change and ability of the organism to adapt in conditions of desynchronosis is confirmed by the results of experimental studies: modeling desynchronosis among primates and studying polymorphism of marker genes of a human-being (in particular, expectant mothers and new born babies) in two model territories with different values of desynchronosis).

The desynchronosis modeled by means of time shift of primate feeding causes a response in the form of stress reaction - increase in production of stress hormones (cortisol and corticosterone) and change in behavioral parameters (nervous condition, crying, aggression). By the end of the second week of being in such conditions of experimental desynchronosis the primates showed an obvious tendency to fading of stress reactions.

The assessment of polymorphism of marker genes didn't reveal any reliable discrepancies between the women citizens of regions differing by desynchronosis values and their new born babies and showed absence of hereditary predisposition to deadaptation in the conditions of desynchronosis.

The assessment of efficiency of implementation of this or that scenario of time keeping in the subject of RF conducted by means of analysis of optimum desynchronosis index formed under a certain scenario showed that under the current distribution of the Russian Federation subjects into time zones there is no analyzed scenario of time keeping that will be optimal for all regions. Moreover, 12 subjects of the Russian Federation reach the optimal values of desynchronosis index under none of the considered scenarios of time keeping.

When implementing the scenario of constant summer time within the whole year the annual average digressions of administrative time from astronomic time in conditions of a significant distribution of regions according to time zones will turn to be non-optimal (under the criterion of minimizing the risk of additional population morbidity) in 43 subjects of RF, in 10 subjects the values of the desynchronosis index will be close to optima and in 30 - optimal.

When implementing the scenario of constant winter time in the conditions of the current distribution according to time zones the digression of administrative time from astronomic time will be non-optimal for already 66 RF subjects, 12 subjects will be close to optimal and 5 optimal. 
When returning the time keeping system presupposing seasonal shifts of time, nonoptimal annual average digressions (under the criterion of minimizing risks of additional population morbidity) will be in 42 RF subjects, the values of the desynchronosis index will be close to optimal in 20 subjects and optimal in 21 subjects.

Time keeping in accordance with its astronomic zone (zonal, geographic) is non-optimal under the criterion of minimizing risks of additional population morbidity in all RF subjects and cannot be considered as an alternative option.

To increase the efficiency (under the criterion of minimizing risks of additional population morbidity) of applying the scenario of time-keeping 'constant summer' it is required to reproduce two time zones (Moscow time +1 hour and Moscow time +9 hours) and taking a decision on redistribution of respective time zones for 25 subjects of the RF. With this, 18 regions will remain with non-optimal parameters of administrative time shift.

To increase the efficiency (under the criterion of minimizing risks of additional population morbidity) of applying the time keeping scenario 'constant winter' it is required to eliminate one (Moscow time minus 1 hour) and reproduction of three time zones (Moscow time plus 1 hour, Moscow time plus 9 hours, Moscow time plus 10 hours) and taking a decision on redistribution of respective time zones for $63 \mathrm{RF}$ subjects.

To increase efficiency (under the criterion of minimizing risks of additional population morbidity) of applying the time keeping scenario 'seasonal transfers to winter and summer time' it is required to reproduce two time zones (Moscow time plus 1 hour and Moscow time plus 9 hours) and taking a decision on redistribution respective of time zones for 22 RF subjects. With this, 20 regions will retain non-optimal parameters of administrative time shift.

\section{Conclusions:}

1. The risk of negative implications for the population health depends on the value of the desynchronosis index expressing the administrative time shift in comparison with the astronomic time.

2. Under the criteria of risks of additional initial morbidity for children population the optimal values of the absolute desynchronosis index are within the range of 56-92 minutes; under the criteria of the risk of additional initial morbidity for adults it is 71-129 minutes.

3. Time keeping in accordance with its astronomic zone (zonal, geographic) is nonoptimal under the criterion of minimizing risks of additional population morbidity in all the RF subjects and cannot be considered as a choice alternative. 
4. Under the current distribution of the subjects of RF into time zones there in no considered scenario of time keeping ('decree annual'; 'decree +1 hour' for the summer period; 'decree +1 hour' annually) that will be optimal for all the regions of RF.

5. The biggest number of the subjects of RF with optimal or close to optimal values of desynchronosis index (under the criterion of risks of additional population morbidity) is achieved under the scenario 'decree +1 hour' annually (constant summer) and 'decree +1 hour' for the summer period (seasonal transfers of clocks winter/summer).

6. Population health risk management in the aspect of harmonization of time keeping system (the choice of this or that scenario) is possible under the criterion of risks of additional morbidity dependent on the absolute desynchronosis index.

\section{References}

1. Alekseev V.B., Lebedeva-Nesevrya N.A., Barg A.O., Dugina O.Yu., Gasnikov V.K. Mediko-sotsial'nye riski desinkhronizatsii administrativnogo i astronomicheskogo vremeni $\mathrm{v}$ otsenkakh naseleniya regionov Rossii [Medical and social risks of jetlag of administrative and astronomical time in the estimates of the population of Russian regions]. Sotsial'nye aspekty zdorov'ya naseleniya, 2012, no. 5. Avaible at: http: //vestnik.mednet.ru/content/view/437/27/lang.ru/.

2. Aprelev V.P. Khronologicheskaya voyna [Chronological war]. Priroda i chelovek. XXI vek, 2009, no. 11, pp. 40-42.

3. Zaytseva N.V., Shur P.Z., May I.V., Kir'yanov D.A. Metodicheskie podkhody k otsenke integral'nogo riska zdorov'yu naseleniya na osnove evolyutsionnykh matematicheskikh modeley [Methodological approaches to evaluating the integral health risk on the basis of evolutional mathematical models]. Zdorov'e naseleniya i sreda obitaniya, 2011, no. 3, pp. 6-9.

4. Novikov N.Yu. Otmena perekhodov na letnee i zimnee vremya v Rossiyskoy Federatsii [Cancel of daylight saving time in the Russian Federation]. Federal'nyy spravochnik, Moscow, 2011, issue 25, pp. 189-194.

5. Panin A.V. Perevedem strelki chasov v posledniy raz [Set the switches for the last time]. Ekologiya i zhizn', 2011, no. 3, pp. 76-78. 